\title{
Endurance exercise training reduces cardiac sodium/calcium exchanger expression in animals susceptible to ventricular fibrillation
}

\author{
Monica Kukielka' , Bethany J. Holycross ${ }^{2}$ and George E. Billman ${ }^{1,3 *}$ \\ 1 Department of Physiology and Cell Biology, The Ohio State University, Columbus, OH, USA \\ 2 Department of Veterinary Biosciences, The Ohio State University, Columbus, OH, USA \\ ${ }^{3}$ Dorothy M. Davis Heart and Lung Research Institute, The Ohio State University, Columbus, OH, USA
}

Edited by:

Timothy I. Musch, Kansas State

University, USA

\section{Reviewed by:}

Karin Sipido, Katholieke Universiteit

Leuven, Belgium

Javier Agustin Sala-Mercado, Wayne

State University, USA

*Correspondence:

George E. Billman, Department of Physiology and Cell Biology, The Ohio

State University, 304 Hamilton Hall,

1645 Neil Avenue, Columbus, $\mathrm{OH}$

43210-1218, USA.

e-mail: billman.1@osu.edu

\begin{abstract}
Aim: Increased sodium/calcium exchanger activity (NCX1, an important regulator of cardiomyocyte cystolic calcium) may provoke arrhythmias. Exercise training can decrease NCX1 expression in animals with heart failure improving cytosolic calcium regulation, and could thereby reduce the risk for ventricular fibrillation (VF). Methods: To test this hypothesis, a 2-min coronary occlusion was made during the last minute of exercise in dogs with healed myocardial infarctions; 23 had VF ( $\mathrm{S}$, susceptible) and 13 did not ( $R$, resistant). The animals were randomly assigned to either 10-week exercise training (progressively increasing treadmill running; $S n=9 ; \mathrm{R} n=8$ ) or 10-week sedentary ( $S n=14 ; R n=5$ ) groups. At the end of the 10-week period, the exercise + ischemia test provoked VF in sedentary but not trained susceptible dogs. On a subsequent day, cardiac tissue was harvested and NCX1 protein expression was determined by Western blot. Results: In the sedentary group, NCX1 expression was significantly (ANOVA, $P<0.05$ ) higher in susceptible compared to resistant dogs. In contrast, NCX1 levels were similar in the exercise trained resistant and susceptible animals. Conclusion: These data suggest that exercise training can restore a more normal NCX1 level in dogs susceptible to VF, improving cystolic calcium regulation and could thereby reduce the risk for sudden death following myocardial infarction.
\end{abstract}

Keywords: ventricular fibrillation, sodium/calcium exchanger, myocardial infarction, myocyte calcium regulation, exercise training

\section{INTRODUCTION}

Abnormal myocyte calcium regulation plays a major role in both contractile dysfunction and an increased risk for arrhythmias associated with cardiac disease (Billman, 1991; Bers, 2002; Bers and Weber, 2002). In particular, myocardial infarction provokes a cascade of adaptive changes in myocyte calcium handling in an attempt to maintain ventricular contractile function but at the expense of an increased risk for ventricular fibrillation (VF; Billman, 1991; Bers, 2002; Bers and Weber, 2002). An excess in intracellular calcium (calcium overload) would activate compensatory mechanisms to promote calcium removal in order to facilitate relaxation (Min et al., 2002). In particular, elevations in diastolic calcium can provoke oscillations in membrane potential (delayed afterdepolarizations) that, if of sufficient magnitude to reach threshold, can trigger extrasystoles (Billman, 1991). These afterdepolarizations have been shown to result primarily from an inward current associated with the activation of the sodium/calcium exchanger (NCX) in the reverse mode (i.e., one $\mathrm{Ca}^{2+}$ out of the cell in exchange with three $\mathrm{Na}^{+}$into the cell; Blaustein and Lederer, 1999; Philipson and Nicoll, 2000; Satoh et al., 2000; Bers and Weber, 2002; Reuter et al., 2005). As such, an overexpression of NCX would enhance this inward current, particularly in a setting of elevated cytosolic calcium as during myocardial ischemia (Billman, 1991), and thereby could promote arrhythmia formation.

Both increases and decreases in NCX function have been described in animal models and patients depending on the cardiovascular disease (Kofuji et al., 1992; Litwin and Bridge, 1997;
O'Rourke et al., 1999; Zhang et al., 1999; Piper et al., 2000; Pogwizd, 2000; Sipido et al., 2000; Wisløff et al., 2000; Pogwizd et al., 2001; Lu et al., 2002; Armoundas et al., 2003; Quinn et al., 2003; Wei et al., 2003; Cheung et al., 2004; Xiong et al., 2005). In the failing heart, or in response to pressure overload, the NCX is upregulated (O'Rourke et al., 1999; Armoundas et al., 2003). Using a rabbit model of heart failure, Pogwizd et al. $(1999,2001)$ demonstrated that activation of NCX provoked an inward (depolarizing) current that produced delayed afterdepolarizations that triggered premature beats. In a similar manner, hypertrophy induced by hypertension increase the expression of NCX that was associated with an increased risk for arrhythmias (Collins et al., 2005). In contrast, less consistent results have been obtained reported following myocardial infarction that did not produce a marked depression in contractile function (Dixon et al., 1992; O’Rourke et al., 1999; Pogwizd et al., 1999; Zhang et al., 1999; Wisløff et al., 2000).

If an enhanced NCX activation contributes to calcium overload and arrhythmia formation, then one would predict that interventions that reduce the expression of this protein should improve myocyte calcium handling and reduce the risk for sudden cardiac death (Ozdemir et al., 2008). Exercise training has been shown to reduce to the risk for arrhythmias in post-myocardial infarction patients and prevent arrhythmias in animal models (for a review see Billman, 2009). Even modest exercise training programs (e. g., walking 1-2 miles/day, Hakim et al., 1998) have been shown to improve cardiac autonomic regulation (Iellamo et al., 2000; 
La Rovere et al., 2002) and decrease mortality in patients with acute myocardial infarction (O'Connor et al., 1989; Hamalainen et al., 1995; Leitch et al., 1997; Steffen-Batey et al., 2000; La Rovere et al., 2002) or arrhythmias in patients in heart failure (Hertzeanu et al., 1993). In a similar manner, exercise training restored a more normal autonomic balance and completely suppressed VF induced by myocardial ischemia in animals with healed anterior myocardial infarctions (Billman et al., 1984, 2006; Billman, 2006, 2009; Billman and Kukielka, 2006, 2007; Kukielka et al., 2006; Holycross et al., 2007). Exercise training can either increase (Tibbits et al., 1989; Wisløff et al., 2000; Mace et al., 2003; Cheung et al., 2004) or decrease (Palmer et al., 1999; Cheung et al., 2004) NCX activity in rats with healthy hearts. In contrast, exercise training reduced elevated NCX levels in animals with heart failure (Lu et al., 2002; Cheung et al., 2004) or hypertrophy induced by hypertension (Collins et al., 2005). Daily voluntary exercise also reduced the susceptibility of ventricular arrhythmias in the hypertensive rats (Collins et al., 2005). The effects of exercise training on NCX expression in animals with myocardial infarction known to be susceptible to $\mathrm{VF}$ remain to be determined.

It, therefore, was the purpose of the present study to evaluate the effects of endurance exercise training on NCX expression in dogs with healed myocardial infarctions that were confirmed to be susceptible to VF. In particular, the hypothesis that endurance exercise training would restore a more normal cardiac NCX expression in animals susceptible to VF was tested.

\section{MATERIALS AND METHODS}

The principles governing the care and use of animals, as expressed in the Guide for the Care and Use of Laboratory Animals published by the US National Institute of Health (NIH publication No. 85-323, revised 1996) and as adopted by the American Physiological Society, were followed at all times during this study. In addition, the Ohio State University Institutional Animal Care and Use Committee approved all the procedures used in this study.

All the studies were performed on archived tissue harvested from dogs that had been randomly assigned to either exercise training or an equivalent sedentary time period. A flow chart of the animals used in the present study is displayed in Figure 1.

\section{SURGICAL PREPARATION}

Sixty heartworm free mongrel dogs weighing $15.4-24.5 \mathrm{~kg}$ $(19.1 \pm 0.4 \mathrm{~kg})$ were used in this study. The animals were anesthetized and instrumented as previously described (Billman et al., 1982, 2006; Schwartz et al., 1984; Houle et al., 2001; Billman, 2006; Billman and Kukielka, 2006, 2007; Kukielka et al., 2006; Holycross et al., 2007). Briefly, $24 \mathrm{~h}$ before surgery, a transdermal fentanyl patch that delivers $100 \mu \mathrm{g} / \mathrm{h}$ (Duragesic, Jansen Pharmaceutica, Titusville, NJ, USA) was placed on the left side of the animal's neck and secured with tape. On the day of surgery, the dogs received $15 \mathrm{mg}$ ( $1 \mathrm{ml}$, i.m.) morphine sulfate (Elkins-Sinn, Cherry Hill, NJ, USA) and thiopental sodium (Baxter Healthcare, Glendale, CA, USA; $20 \mathrm{mg} / \mathrm{kg}$, i.v.) to induce anesthesia. The dogs were intubated and a surgical plane of anesthesia was maintained by the inhalation of isoflurane (1-1.5\%, Baxter Healthcare, Glendale, CA, USA). Using strict aseptic procedures, a left thoracotomy was made in the fourth intercostal space. The heart was exposed and supported by a pericardial cradle. The left circumflex coronary artery was dissected free of the surrounding tissue. Both a $20-\mathrm{MHz}$ pulsed Doppler flow transducer and a hydraulic occluder were then placed around this vessel. Two pairs of silver coated copper wires were also sutured on the epicardial surface of the heart and used to obtain a ventricular electrogram. One pair of electrodes was placed in the potentially ischemic area (lateral left ventricular wall, an area perfused by the left circumflex artery) and the other pair in a non-ischemic region (right ventricular out flow tract). A two-stage occlusion of the left anterior descending artery was then performed approximately one-third the distance from its origin in order to produce an anterior wall myocardial infarction. This vessel was partially occluded for $20 \mathrm{~min}$ and then tied off. The leads to the cardiovascular instrumentation were tunneled under the skin to exit on the back of the animal's neck.

In addition to the fentanyl patch described above, morphine sulfate $(1.0 \mathrm{mg} / \mathrm{kg}$ s.c.) was given as needed to control any postoperative pain. The long-lasting local anesthetic $0.25 \%$ bupivacaine $\mathrm{HCl}$ (Abbott Laboratories, North Chicago, IL, USA) was injected in each of three sites $(0.5 \mathrm{ml})$ to block the intercostals nerves in the area of the incision to minimize discomfort to the animals. Each dog was placed on antibiotic therapy (amoxicillin, Teva Pharmaceuticals, Sellersville, PA, USA; $500 \mathrm{mg} /$ o.s.) twice daily for 7 days. The animals were placed in a quiet recovery area and were returned to their home kennel once the effects of the anesthesia had dissipated. To minimize the incidence of arrhythmias, the dogs received $100 \mathrm{mg}$ of lidocaine $\mathrm{HCl}$ (i.m.; Elkin-Sinns, Cherry Hill, NJ, USA) before surgery, which was supplemented (60 mg i.v.) before each stage of the two-stages of the coronary occlusion. The dogs also received $500 \mathrm{mg}$ of procainamide $\mathrm{HCl}$ (i.m; Abbott Laboratories, North Chicago, IL, USA) before the surgery.

\section{Exercise plus ischemia test: classification of the dogs}

The studies began 3-4 weeks after the production of the myocardial infarction (see flow chart, Figure 1). The susceptibility to VF was tested as previously described (Billman et al., 1982, 2006;

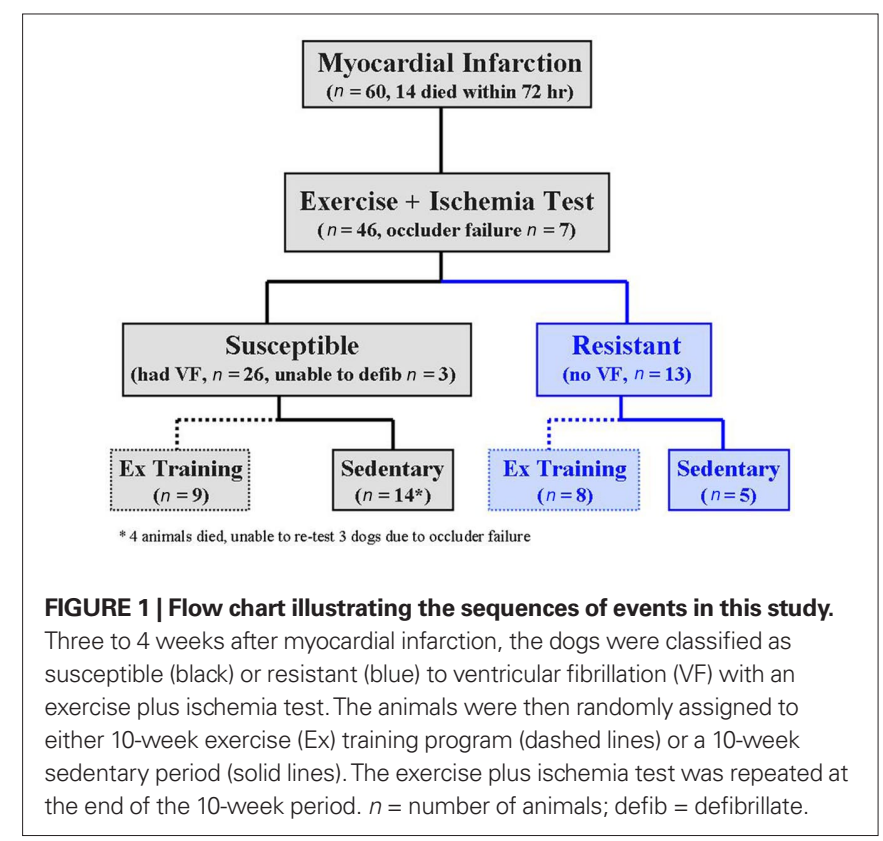


Schwartz et al., 1984; Houle et al., 2001; Billman, 2006; Billman and Kukielka, 2006, 2007; Kukielka et al., 2006; Holycross et al., 2007). Briefly, the animals ran on a motor-driven treadmill while workload progressively increased until a heart rate of $70 \%$ of maximum (approximately 210 beats $/ \mathrm{min}$ ) had been achieved. During the last minute (on average during the 18th minute) of exercise, the left circumflex coronary artery was occluded, the treadmill stopped, and the occlusion maintained for an additional minute (total occlusion time $=2 \mathrm{~min}$ ). The exercise plus ischemia test reliably induced ventricular flutter that rapidly deteriorated into VF. Therefore, large defibrillation electrodes (Stat-padz, Zoll Medical, Burlington, MA) were placed across the animal's chest so that electrical defibrillation (Zoll M series defibrillator, Zoll Medical, Burlington, MA, USA) could be achieved with a minimal delay but only after the animal was unconscious (10-20 s after the onset of VF). Sixty dogs underwent surgery; 21 animals could not be tested either due to death within $72 \mathrm{~h}$ of the myocardial infarction $(n=14,23.3 \%)$ or occluder failure $(n=7)$. Thus, the exercise plus ischemia test was performed on 39 of the original 60 animals. The occlusion was immediately released if VF had occurred. Twenty-six dogs developed VF (susceptible) while the remaining 13 did not (resistant). Three susceptible animals were not successfully defibrillated and thus were not available for additional studies. This exercise plus ischemia test was repeated, using the same exercise intensity, after the completion of the 10-week exercise training or 10-week sedentary time period (see below).

\section{EXERCISE TRAINING PROTOCOL}

The susceptible $(n=23)$ and the resistant $(n=13)$ dogs were randomly assigned to either a 10-week exercise training period (susceptible $n=9$, resistant $n=8$ ) or an equivalent sedentary period (susceptible $n=14$, resistant $n=5$; Figure 1). The dogs in the exercise training group ran on a motor-driven treadmill for 10-weeks, 5 days/week at approximately $70-80 \%$ of maximum heart rate. The exercise intensity and duration progressively increased as follows: 1 st week, $20 \mathrm{~min}$ at $4.8 \mathrm{kph} / 0 \%$ grade; 2 nd week, $40 \mathrm{~min}$ at $5.6 \mathrm{kph} / 10 \%$ grade; $3 \mathrm{rd}$ week, $40 \mathrm{~min}$ at $6.4 \mathrm{kph} / 10 \%$ grade; 4th week, $60 \mathrm{~min}$ at $6.4 \mathrm{kph} / 10 \%$ grade; 5 th week, $60 \mathrm{~min}$ at $6.4 \mathrm{kph} / 12 \%$ grade; 6 th week, $75 \mathrm{~min}$ at $6.4 \mathrm{kph} / 12 \%$ grade, 7 th week, $90 \mathrm{~min}$ at $6.4 \mathrm{kph} / 12 \%$ grade; 8 th-10th week, $90 \mathrm{~min}$ at $6.4 \mathrm{kph} / 14 \%$ grade. Each exercise session included 5 -min warm-up and 5-min cool-down periods (running at a low intensity, $0 \%$ grade and speed, $4.8 \mathrm{kph}$ ). The dogs in the sedentary group were placed in transport cage for equivalent time periods but without exercise. All 17 animals (both susceptible and resistant dogs) in the exercise group successfully completed the training program. Four dogs in the susceptible sedentary group died spontaneously between the 6th and 10th week of the sedentary period and were eliminated from the study. The exercise plus ischemia test could not be repeated in three of the sedentary susceptible animals due to failure of the coronary occluder and were also eliminated from the study (Figure 1).

\section{Western blot analysis}

After the completion of the 10-week exercise training or 10-week sedentary period, the dogs were euthanized with pentobarbital sodium $(100 \mathrm{mg} / \mathrm{kg}$, i.v.; Nembutal, Ovation Pharmaceuticals Inc., Deerfield, IL, USA). The heart was rapidly excised and left ventricular tissue samples were flash frozen in liquid nitrogen and then stored at $-80^{\circ} \mathrm{C}$ for future analysis. The left ventricular samples were obtained from posterolateral free wall (i.e., remote from the infarction). Left ventricular tissue from five dogs per treatment group was selected at random for Western blot analysis. In order to confirm the reproducibility of the results, the analysis was performed twice on separate days, once each by two different individuals (Monica Kukielka and Bethany J. Holycross).

Samples were analyzed using the method of Han et al. (2002). Briefly, approximately $100 \mathrm{mg}$ of tissue was pulverized in liquid nitrogen using a cooled mortar and pestle. The pulverized tissue was then place in labeled microcentrifuge tubes with $500 \mu \mathrm{l}$ of ice-cold Tris-EDTA buffer (Tris $20 \mathrm{mmol} / \mathrm{L}$, EDTA $1 \mathrm{mmol} / \mathrm{L}$, benzamidine $0.1 \mathrm{mg} / \mathrm{mL}$, phenylmethylsulfonyl fluoride $10 \mathrm{mg} / \mathrm{mL}$, leupeptin $5 \mu \mathrm{g} / \mathrm{mL}$, pepstatin A $5 \mu \mathrm{g} / \mathrm{mL}$, aprotinin $5 \mu \mathrm{g} / \mathrm{mL}$, and sodium orthovanadate $100 \mu \mathrm{mol} / \mathrm{L})$. Triton-X $100(2 \%)$ was added and the samples were incubated on ice for $2 \mathrm{~h}$. The samples were then centrifuged for $10 \mathrm{~min}$ at $14,000 \mathrm{~g}$ in $4^{\circ} \mathrm{C}$.

Protein concentrations were determined using a bicinchoninic acid (BCA) kit (Pierce Biotechnology Inc., Rockford, IL, USA). In the present study, $100 \mu \mathrm{g}$ of protein were denatured in $3 \times \mathrm{SDS} / 30 \times$ dithiothreitol (DTT) Blue Loading Buffer (New England Biolabs, Ipswich, MA, USA), $25 \mu \mathrm{g}$ of protein were separated on a 7.5\% reducing precast $\mathrm{HCl}-$ Tris gels (Bio-Rad), and transferred to Immobilon-P polyvinylidene difluoride membranes. Membranes were blocked ( $2 \mathrm{~h}$, room temperature) with $5 \%$ non-fat milk in $0.1 \%$ Tween 80 Tris-buffered saline solution (TTBS) and incubated overnight at $4^{\circ} \mathrm{C}$ mouse monoclonal antibody against NCX1, 1:1,000 (Bioreagents, Golden, CO, USA) and the samples were normalized to Calsequestrin, 1:2,500 (Bioreagents, Golden, CO, USA). Following incubation overnight with the primary antibodies, the membranes were washed in TTBS (Han et al., 2002) and then were incubated in goat anti-mouse IgM 1:5000 (Santa Cruz Biotechnology, Santa Cruz, CA, USA) and goat anti-rabbit IgG, 1:5000 (Santa Cruz Biotechnology, Santa Cruz, CA, USA), in 5\% non-fat milk in TTBS (60 min, room temperature), followed by three additional washes in TTBS.

Antibodies were detected using LumiGLO ${ }^{\circ}$ Chemiluminescent Substrate (Upstate Cell Signaling Solutions, Charlottesville, VA, USA). Band density was quantified using Non-linear Dynamics (Durham, NC, USA) Total lab (TL100) software.

\section{Data analysis}

All data are reported as the mean \pm SE of the mean. As previously mentioned, Western blot analysis was performed twice. The results for the two analyses were averaged for each animal (to obtain one average value for each animal). In addition, NCX1 exhibited two distinct bands ( 160 and $120 \mathrm{kDa}$ ). These data were combined to obtain the total NCX1 Protein levels. A two-way ANOVA [group (2 levels) $\times$ treatment ( 2 levels)] was used to determine any differences between groups (susceptible vs. resistant) and treatment (exercise vs. sedentary). A three factor (group (2 levels), treatment (2 levels), and exercise level (2 levels)] ANOVA with repeated measures on two factors (treatment and exercise level) was used to compared heart rate and heart rate variability data. As required for repeated measures designs, the homogeneity of covariance (sphericity assumption, equal correlates between the treatments) was tested using 
Mauchly's test and, if appropriate, adjusted using Huynh-Feldt correction. If the $F$ ratio exceeded a critical value $(P<0.05)$, then Scheffe's test was used to compare the groups means. The data were analyzed using NCSS statistical software (Kaysville, UT, USA).

\section{RESULTS \\ NCX1 EXPRESSION}

Three isoforms of the NCX have been identified in mammalian species; NCX1, NCX2, and NCX3 (Nicoll et al., 1990; Blaustein and Lederer, 1999; Wakimoto et al., 2000). NCX1 is the dominant isoform expressed canine cardiac tissue (Nicoll et al., 1990; Kofuji et al., 1992; Lee et al., 1994; Blaustein and Lederer, 1999; Philipson and Nicoll, 2000) and is located at three bands when using SDSPAGE gels; 70, 120, and 160-kDa. The appearance and intensity of the bands is dependant on reducing conditions. Using a reducing agent such as DTT to reduce disulfide bonds, the $120-\mathrm{kDa}$ band is most prominent (Shigekawa and Iwamoto, 2001); whereas, under non-reducing conditions the $160-\mathrm{kDa}$ band is more pronounced (Santacruz-Toloza et al., 2000).

In the present study, left ventricular tissue NCX1 expression was noted in the 120 - and $160-\mathrm{kDa}$ bands, but not in the $70-\mathrm{kDa}$ band. Since similar changes were noted in both the 120- and 160$\mathrm{kDa}$ bands, these data were combined for all subsequent analysis. As is displayed in Figure 2, left ventricular tissue NCX1 expression was significantly higher (group effect $P<0.005$, treatment effect $P<0.003$, group $\times$ treatment interaction, $P<0.02$ ) in susceptible sedentary group as compared to either the susceptible exercise trained or the resistant sedentary group. In contrast, no differences were noted between the resistant sedentary, and either the resistant exercise trained or the susceptible exercise trained animals following 10-weeks of exercise training (Figure 2).

\section{EXERCISE TRAINING CONFIRMATION}

Body weight was similar in both sedentary and trained animals for either the resistant (trained $20.4 \pm 1.1$, sedentary $19.6 \pm 1.8 \mathrm{~kg}$ ) or the susceptible (trained $20.0 \pm 0.6$, sedentary $19.8 \pm 0.8 \mathrm{~kg}$ ) dogs. We have previously reported that the exercise training program used in the present study provoked significant cardiac autonomic neural and skeletal muscle adaptations (Billman, 2006; Billman and Kukielka, 2006, 2007; Billman et al., 2006; Kukielka et al., 2006; Holycross et al., 2007). Diaphragm citrate synthase activity was higher $(P<0.05)$ in trained compared to sedentary animals $(n=10$ each; post exercise training $11.6 \pm 1.0 \mathrm{vs}$. sedentary $7.5 \pm 1.4 \mu \mathrm{mol} / \mathrm{ml} / \mathrm{min})$. Exercise training also provoked significant $(P<0.01)$ reductions in the heart rate response to submaximal exercise that were accompanied by significant increases in heart rate variability (vagal activity index; i.e., 0.24-1.04 Hz component of the R-R interval variability) while these variables did not change in the sedentary animals (see Table 1). When considered together, these data confirm that the exercise training program was effective (i.e., there were significant skeletal muscle and cardiac autonomic neural adaptations induced by the training program).

As previously reported (Billman et al., 1984, 2006; Billman, 2006; Billman and Kukielka, 2006, 2007; Kukielka et al., 2006; Holycross et al., 2007), exercise training completely suppressed VF induced by the exercise plus ischemia test (all nine dogs were protected from $\mathrm{VF}$ ). In contrast, VF was still induced in the all of the sedentary susceptible animals $(n=7)$ that were tested at the end of the

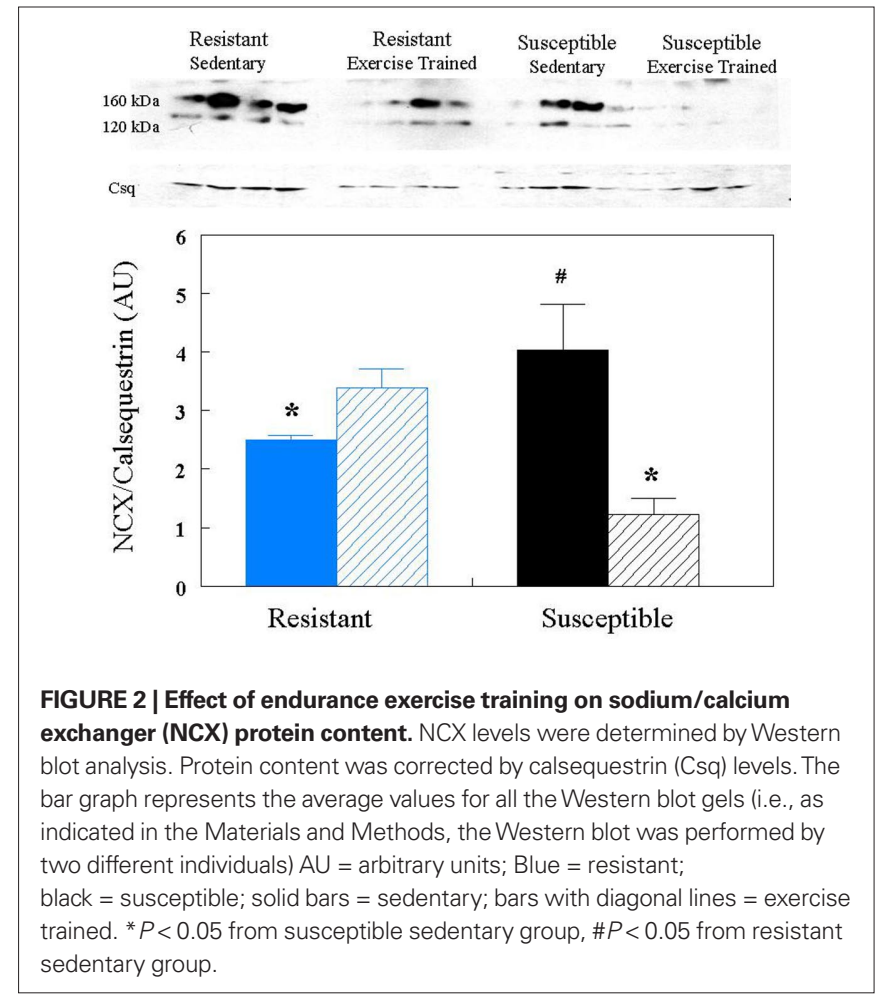

Table 1 |The heart rate and heart rate variability responses to submaximal exercise.

\begin{tabular}{lcclll}
\hline & \multicolumn{2}{c}{ Pre } & & \multicolumn{2}{c}{ Post } \\
\cline { 2 - 3 } \cline { 5 - 6 } & Baseline & Peak & & Baseline & Peak \\
\hline HEART RATE & (BEATS/MIN) & & & \\
Sedentary & $119.1 \pm 4.3$ & $209.4 \pm 6.0$ & & $116.7 \pm 5.1$ & $211.0 \pm 5.2$ \\
Ex train & $118.2 \pm 6.2$ & $209.0 \pm 7.4$ & & $113.2 \pm 4.3$ & $184.4 \pm 5.3^{*}$ \\
HEART RATE VARIABILITY & $\left(\mathbf{I n} \mathbf{~ m s}^{2}\right)$ & & & \\
Sedentary & $7.5 \pm 0.4$ & $1.2 \pm 0.1$ & & $7.4 \pm 0.4$ & $1.5 \pm 0.3$ \\
Ex train & $7.3 \pm 0.3$ & $1.0 \pm 0.3$ & & $8.2 \pm 0.3^{*}$ & $2.4 \pm 0.3^{*}$ \\
\hline
\end{tabular}

Sedentary $n=10$, exercise trained (ex train) $n=14 ;{ }^{*} P<0.01$ pre vs. post.

10-week sedentary period; three animals could not be tested due to failure of the hydraulic occluder. It is also important to note that four dogs in the sedentary group (but none in the exercise training group) died during the 10 -week sedentary period. The exercise plus ischemia test failed to induce ventricular tachyarrhythmias in any resistant dog either before or after the 10-week sedentary or 10-week endurance exercise training period.

\section{DISCUSSION}

The major findings of the present study are: (1) NCX1 expression is increased in sedentary animals susceptible to VF compared to sedentary dogs that were resistant to malignant arrhythmias; and, (2) A 10-week endurance exercise training program significantly reduced NCX1 expression in dogs previous shown to be susceptible to VF but did not alter this protein content in animals that were resistant to life-threatening arrhythmias. In fact, differences were no 
longer noted between the resistant (sedentary or exercise trained) and the exercise trained susceptible animals. These data suggest that NCX1 may be upregulated following myocardial infarction in animals susceptible to VF and further that endurance exercise training reduced this elevated NCX1 level. Thus, exercise training could help restore a more normal myocyte calcium balance and as a consequence, decrease the risk for sudden cardiac death.

\section{SODIUM/CALCIUM EXCHANGER AND CARDIAC DISEASE}

It has been proposed that abnormal calcium regulation in diseased hearts contributes not only to contractile dysfunction, but also to the development of malignant arrhythmias (Billman, 1991; Sipido et al., 2000; Bers, 2002; Bers and Weber, 2002; Rubart and Zipes, 2005). It is well established that elevated cytosolic calcium (calcium overload) can provoke oscillations in membrane potential (delayed afterdepolarizations) that, if of sufficient magnitude to reach threshold, can trigger extrasystoles (Billman, 1991). These afterdepolarizations have been shown to result primarily from an inward current associated with the activation of the sodium/calcium in the reverse mode (i.e., one $\mathrm{Ca}^{2+}$ out of the cell in exchange with three $\mathrm{Na}^{+}$into the cell; Philipson and Nicoll, 2000; Satoh et al., 2000; Bers and Weber, 2002). As such, an overexpression of NCX, particularly in a setting of elevated cytosolic calcium as could occur during myocardial ischemia (Billman, 1991), would prove to be particularly arrhythmogenic. In agreement with the present study, several investigators reported both an increased NCX1 expression (protein and/or mRNA) and an increase in lethal arrhythmia development (triggered by delayed afterdepolarizations) in animal models of heart failure (Pogwizd et al., 1999, 2001; Sipido et al., 2000; Armoundas et al., 2003). In a similar manner, heart failure provoked increases in NCX1 expression coupled with a decreases in SERCA levels in both patients and animals (O'Rourke et al., 1999; Pogwizd et al., 1999, 2001; Wisløff et al., 2000; Lu et al., 2002; Schillinger et al., 2002; Armoundas et al., 2003; Quinn et al., 2003; Wei et al., 2003). It is well established that patients with the greatest left ventricular function following myocardial infarction also have the greatest risk for sudden death (Bigger et al., 1984).

In contrast to results obtained with heart failure, less consistent changes in NCX1 expression have been reported following myocardial infarction (Dixon et al., 1992; O’Rourke et al., 1999; Pogwizd et al., 1999, 2001; Zhang et al., 1999; Wisløff et al., 2000; Cheung et al., 2004). NCX1 expression has been reported to increase (O'Rourke et al., 1999; Pogwizd et al., 1999, 2001; Wisløff et al., 2000; Cheung et al., 2004), to decrease (Dixon et al., 1992; O’Rourke et al., 1999; Zhang et al., 1999; Wisløff et al., 2000; Cheung et al., 2004; Song et al., 2004), or not to change (Schillinger et al., 2002; Mace et al., 2003; Cheung et al., 2004) following myocardial infarction. For example, NCX1 expression in myocytes isolated from post-infarcted rabbit hearts either increased by 32\% (Litwin and Bridge, 1997; Cheung et al., 2004) or decreased by 33\% (Quinn et al., 2003; Cheung et al., 2004). Dixon et al. (1992) found depressed $\mathrm{Na}^{+}$-dependent $\mathrm{Ca}^{2+}$ uptake in cell membrane vesicles isolated from rat hearts 4,8 , and 16 week post-infarction. However, if the infarction culminated in heart failure, then more consistent increases in NCX1 expression were noted (O'Rourke et al., 1999; Pogwizd et al., 1999, 2001; Sipido et al., 2000; Schillinger et al., 2002; Armoundas et al., 2003). Thus, the severity of the injury following infarction may play a critical role in the NCX1 response.

\section{EXERCISE TRAINING AND SODIUM/CALCIUM EXCHANGER}

The effective management of arrhythmias following myocardial infarction remains elusive. In fact, several initially promising antiarrhythmic drugs have actually been shown to increase, rather than to decrease, the risk for arrhythmic death in patients recovering from myocardial infarction (Echt et al., 1991; Waldo et al., 1996). Alternative approaches merit consideration. Accumulating experimental and clinical evidence indicates that exercise training may protect against the development of arrhythmias and the incidence of sudden cardiac death (for a review see Billman, 2009). A 10-week endurance exercise training program completely suppressed VF induced by myocardial ischemia in dogs with healed myocardial infarctions (Billman and Kukielka, 2006; Billman et al., 2006; Holycross et al., 2007). In contrast, a similar sedentary period, not only failed to prevent these malignant arrhythmias but approximately $30 \%$ of the dogs died spontaneously during the 10-week period (Billman and Kukielka, 2006; Billman et al., 2006; Holycross et al., 2007). Exercise training provoked a more favorable autonomic balance (enhanced cardiac vagal and reduced cardiac $\beta_{2}$-adrenoceptor sensitivity; Billman and Kukielka, 2006, 2007; Billman et al., 2006; Kukielka et al., 2006; Holycross et al., 2007) that in turn, could improve myocyte calcium handling. It is possible that exercise training induced changes in NCX1 expression could contribute to an improvement in cardiac myocyte calcium regulation and, thereby, decrease the risk for arrhythmias.

There are only a few studies that have examined the effects of exercise training on NCX1 expression. Both increases (Tibbits et al., 1989; Wisløff et al., 2000; Cheung et al., 2004) and decreases (Palmer et al., 1999; Cheung et al., 2004) in NCX1 activity have been reported following exercise training in rats with healthy hearts. In contrast, exercise training elicited beneficial changes in NCX1 levels in models of cardiovascular disease. In agreement with the present study, Zhang et al. (1998) reported that high intensity sprint training reduced NCX activity and decreased sarcoplasmic reticular calcium contents in myocytes obtained from the hearts of rats with a moderate-sized left ventricular infarct. In a similar manner, exercise training reversed the increased expression of NCX1 and decreased SERCA activity (i.e., SERCA and NCX1 protein levels following training were similar to values for the normal hearts) in a canine model of tachycardia-pacing induced heart failure ( $\mathrm{Lu}$ et al., 2002). Sedentary hypertensive rats that were prone to arrhythmia development exhibited an increased NCX1 expression and decreased phospholamban expression compared to normotensive rats (Collins et al., 2005). Daily exercise both reduced arrhythmia formation and normalized phospholamban and NCX1 expression in the hypertensive rats (Collins et al., 2005). In contrast, Wisløff et al. (2000) reported that myocardial infarction decreased (rather than increased) NCX1 expression (by 30\%) in infarcted rats compared to sham treated animals. Interestingly, exercise training elicited beneficial changes even in this study (Wisløff et al., 2000). NCX1 expression increased in trained rats with or without infarction (Wisløff et al., 2000) such that, after training, NCX1 levels in the infarcted rats no longer differed from the values observed in the sedentary sham group (Wisløff et al., 2000). Thus, in agreement with the present study, exercise training can lower NCX expression, thereby improving myocyte calcium handling and reducing the risk for malignant arrhythmias. 
The mechanisms by which exercise training reduces NCX levels and prevents VF remain to be determined. However, one could speculate that exercise induced changes in cardiac autonomic balance may contribute significantly to these changes. A number of studies demonstrate that cardiac autonomic neural remodeling (i.e., increased sympathetic coupled with reduced parasympathetic activity) following myocardial infarction is associated with an enhanced risk for sudden cardiac death (for a review see Billman, 2009). It is well established that endurance exercise can improve cardiac autonomic balance, both increasing parasympathetic and reducing sympathetic activity (Billman, 2009). To date, a direct adrenergic regulation of NCX via phosphorylation has not been convincingly established in the mammalian heart (Zhang and Hancox, 2009). Ginsburg and Bers (2005), in fact, concluded that any modulation of NCX function by beta-adrenergic receptor stimulation would result secondary to alterations in intracellular $\mathrm{Na}^{+}$or $\mathrm{Ca}^{2+}$. Thus, exercise training induced restoration of a more a normal cardiac autonomic balance most likely would only indirectly influence NCX function. For example, reduced adrenergic activity that occurs as consequence of exercise training would tend to reduce cytosolic calcium levels (less calcium entry via non-phosphorylated L-type calcium channels). As such, less calcium would need to be removed from the cytosol during each cardiac cycle by NCX in exercise trained as compared to sedentary individuals, thereby decreasing the arrhythmogenic inward current associated with the reverse mode (one $\mathrm{Ca}^{2+}$ out for every three $\mathrm{Na}^{+}$in) of this ion exchanger. In a similar manner, it is now clear that adrenergic regulation of NCX can also be indirectly achieved via action on phospholemman, a protein that regulates $\mathrm{Na}^{+} / \mathrm{K}^{+}$ATPase activity (Despa et al., 2005, 2008; Wang et al., 2010). Adrenergically mediated phosphorylation of phospholemman would relieve an inhibition of the sarcolemmal $\mathrm{Na}^{+} / \mathrm{K}^{+}$ATPase to lower cytosolic sodium (Despa et al., 2005, 2008; Wang et al., 2010). As a consequence, calcium efflux via NCX would be favored, producing an inward current that would tend to prolong action potential duration and to induce membrane afterdepolarizations. Thus, exercise training could reduce cardiac adrenergic activation and thereby indirectly attenuate activation of the reverse mode of NCX. If this hypothesis is correct, then one would predict that, in addition to actions on calcium regulatory proteins, exercise training should also reduce either phospholemman expression or its activity (phosphorylation status). If this prediction is confirmed, then phospholemman could prove to be a novel anti-arrhythmic target. Additional studies are required to test these hypotheses.

\section{LIMITATIONS OF THE STUDY}

The present study only examined the effects of exercise training on one calcium regulatory protein, the NCX. Many additional proteins regulate cystolic calcium. For example, L-type calcium channels located in cell membrane and calcium-release channels, ryanodine receptors, located within the sarcoplasmic reticulum (SR) both contribute to the regulation of intracellular calcium (Bers, 2002). In similar manner, calcium removal during diastole depends primarily on two mechanisms a SR Ca ${ }^{2+}$-ATPase (SERCA, calcium pump), and the sarcolemmal NCX (Bers, 2002; Bers and Weber, 2002). Alterations in one or more of these proteins could also contribute to an abnormal calcium handling and corresponding contractile dysfunction and vulnerability to arrhythmias following myocardial infarction. Furthermore, it must be emphasized that changes in protein expression do not necessarily result in corresponding alterations in function (that is, expression assays only measure the amount of the protein present and not whether the protein is physiologically active). The effects of exercise training on the expression and activity of these important regulatory proteins were not investigated in the present study and remain to be determined.

As previously noted, heart failure elicited the most consistent increases in NCX expression. As such, the higher NCX expression noted in the dogs susceptible to VF may reflect a relatively greater impairment in ventricular function due to larger myocardial infarctions in these animals. Myocardial infarction size was not measured in the present study, as the hearts were removed for the in vitro NCX analysis. However, previous studies demonstrated that susceptible dogs had larger infarctions $(n=93,17.7 \pm 0.9 \%)$ as compared to resistant dogs $(n=50,12.6 \pm 1.4 \%$; Billman, 2006). Despite the larger myocardial infarction, baseline echocardiographic indices of contractile function (i.e., fractional shortening, velocity of circumferential fiber shortening, etc.,) were similar in susceptible and resistant dogs both before and after myocardial infarction (Houle et al., 2001; Billman, 2006, Billman et al., 2006; Holycross et al., 2007). However, the susceptible animals exhibited larger increases in left ventricular end diastolic pressure during submaximal exercise than were noted for the resistant dogs (Billman et al., 1985; Billman, 2006). As such, the dogs susceptible to VF, while not in overt heart failure, exhibited greater contractile deficits when the heart was challenged by a metabolic stressor (exercise) than did animals that were resistant to malignant arrhythmias. Although it is not likely that exercise training would alter myocardial infarction size (as the exercise program did not begin until after the myocardial infarction was healed, at least 4 weeks after the induction of the infarction), it is possible that the training improved ventricular function, thereby removing the stimulus for the NCX upregulation.

In summary, animals proven to be susceptible to VF exhibited an increased expression of NCX1 as compared to dogs resistant to malignant arrhythmias. Exercise training significantly reduced NCX1 expression to a greater extent in the dogs that were susceptible to ischemically induced VF than was noted in the animals were resistant to malignant arrhythmias; such that differences were no longer noted between the resistant and susceptible animals following a 10-week exercise training program. As previously reported (Billman et al., 1984, 2006; Billman and Kukielka, 2006; Holycross et al., 2007), exercise training also prevented VF induced by myocardial ischemia in the susceptible dogs. When considered together, these data suggest that abnormal calcium handling could contribute significantly to a greater risk for malignant arrhythmias. Furthermore, endurance exercise training can improve NCX expression in animals with healed myocardial infarctions, restoring a more normal cardiac calcium regulation and could thereby reduce the risk for lethal cardiac arrhythmias.

\section{ACKNOWLEDGMENTS}

The studies were supported by National Heart Lung and Blood Institute grant HL-68609. The research was performed as partial fulfillment for the requirements for the Master of Science Degree (to Monica Kukielka). 


\section{REFERENCES}

Armoundas, A. A., Hobai, I. A., Tomaselli, G. F., Winslow, R. L., and O'Rourke, B. (2003). Role of sodium-calcium exchange in modulating the action potential of ventricular myocytes from normal and failing hearts. Circ. Res. 93, 46-53.

Bers, D. M. (2002). Cardiac excitationcontraction coupling. Nature 415, 198-205.

Bers, D. M. and Weber, C. R. (2002). Na/ Ca exchange function in intact ventricular myocytes. Ann. N. Y. Acad. Sci. 976, 500-512.

Bigger, J. T. Jr., Fleiss, J. L., Kleiger, R., Miller, J. P., Rolnitzky, M., and The Multicenter Post-Infarction Research Group. (1984). The relationship among ventricular arrhythmias, left ventricular dysfunction, and mortality in the 2 years after myocardial infarction. Circulation 69, 250-258.

Billman, G. E. (1991). The antiarrhythmic and antifibrillatory effects of calcium antagonists. J. Cardiovasc. Pharmacol. 18(Suppl. 10), S107-S117.

Billman, G. E. (2006). A comprehensive review and analysis of 25 years of data from an in vivo canine model of sudden cardiac death: implications for future anti-arrhythmic drug development. Pharmacol. Ther. 111, 808-835.

Billman, G. E. (2009). Cardiac autonomic neural remodeling and susceptibility to sudden cardiac death: effect of endurance exercise training. Am. J. Physiol. Heart Circ. Physiol. 297, H1171-H1193.

Billman, G. E., and Kukielka, M. (2006). Effect of exercise training on heart rate variability and susceptibility to sudden cardiac death: protection is not due to enhanced cardiac vagal regulation. $J$. Appl. Physiol. 100, 896-906.

Billman, G. E., and Kukielka, M. (2007). Effect of endurance exercise training on the heart rate onset and heart rate recovery responses to submaximal exercise in animals susceptible to ventricular fibrillation. J. Appl. Physiol. 102, 231-240.

Billman, G. E., Kukielka, M., Kelley, R., Mustafa-Bayoumi, M., and Altschuld, R.A. (2006). Endurance exercise training attenuates cardiac $\beta_{2}$-adrenoceptor responsiveness and prevents ventricular fibrillation in animals susceptible to sudden death. Am. J. Physiol. Heart Circ. Physiol. 290, H2590-H2599.

Billman, G. E., Schwartz, P. J., Gagnol, J. P., and Stone, H. L. (1985). The cardiac response to submaximal exercise in dogs susceptible to sudden cardiac death. J. Appl. Physiol. 59, 890-897.

Billman, G. E., Schwartz, P. J., and Stone, H. L. (1982). Baroreceptor reflex control of heart rate: a predictor of sudden cardiac death. Circulation 66, 874-880.

Billman, G. E., Schwartz, P. J., and Stone, H. L. (1984). The effects of daily exercise on susceptibility to sudden cardiac death. Circulation 69, 1182-1189.

Blaustein, M. P., and Lederer, W. J. (1999). Sodium/calcium exchange: its physiological implications. Physiol. Rev. 79, 763-854.

Cheung, J.Y., Song, J., Rothblum, L. I., and Zhang, X.-Q. (2004). Exercise training improves cardiac function postinfarction: special emphasis on recent controversies on $\mathrm{Na}+-\mathrm{Ca} 2+$ exchanger. Exerc. Sport Sci. Rev. 32, 83-89.

Collins, H. L., Loka, A. M., and DiCarlo, S. E. (2005). Daily exercise-induced cardioprotection is associated with changes in calcium regulatory proteins in hypertensive rats. Am. J. Physiol. Heart Circ. Physiol. 288, H532-H540.

Despa, S., Bossuyt, J., Han, F., Ginsburg, K. S., Jia, L. G., Kutchai, H., Tucker, A. L., and Bers, D. M. (2005). Phospholemman-phosphorylation mediates the beta-adrenergic effects of $\mathrm{Na} / \mathrm{K}$ pump function in cardiac myocytes. Circ. Res. 97, 252-259.

Despa, S., Tucker, A. L., and Bers, D. M. (2008). PLM-mediated activation of $\mathrm{Na} / \mathrm{K}$-ATPase limits $[\mathrm{Na}]_{\mathrm{i}}$ and inotopic state during $\beta$-adrenergic stimulation in mouse ventricular myocytes. Circulation 117, 1849-1885.

Dixon, I. M. C., Hata, T., and Dhalla, N. S. (1992). Sarcolemmal calcium transport in congestive heart failure due to myocardial infarction in rats. Am. J. Physiol. Heart Circ. Physiol.262, H1387-H1394.

Echt, D. S., Liebson, P. R., Mitchell, L. B., Peters, R. W., Obiasmanno, D., Baker, A. H., Arensberg, D., Freedman, L., Greene, H. L., Hunter, M. L., and Richardson, D. W. (1991). Mortality and morbidity in patients receiving encaindie, flecainide, or placebo. $N$. Engl. J. Med. 324, 782-788.

Ginsburg, K. S., and Bers, D. M. (2005). Isoproterenol does not enhance $\mathrm{Ca}$-dependent $\mathrm{Na} / \mathrm{Ca}$ exchange current in intact .rabbit ventricular myocytes. J. Mol. Cell. Cardiol. 39, 972-981.

Hakim, A. A., Petrovitch, H., Burchfiel, C. M., Ross, G. W., Rodriguez, B. L., White, L. R., Yano, K., Curb, J. D., and Abbott, R. D. (1998). Effects of walking on mortality among nonsmoking retired men. N. Engl. J. Med. 338, 94-99.

Hamalainen, H., Luurila, O. J., Kallio, V., and, Knuts, L. R. (1995). Reduction in sudden death and coronary mortality in myocardial infarction after rehabilitation. 15 year follow-up study. Eur. Heart. J. 16, 1839-1844.

Han, W., Bao, W., Wang, Z., and Nattel, S. (2002). Comparison of ion-channel subunit expression in canine cardiac Purkinje fibers and ventricular muscle. Circ. Res. 91, 790-797.

Hertzeanu, H. L., Shermesh, J., and Aron, L. A. (1993). Ventricular arrhythmias in rehabilitated and nonrehabilitated post-myocardial infarction patients with left ventricular dysfunction. Am J. Cardiol. 71, 24-27.

Holycross, B. J., Kukielka, M., Nishijima, Y., Altschuld, R. A., Carnes, C. A., and Billman, G.E. (2007). Exercise training normalizes $\beta$-adrenoceptor expression in dogs susceptible to ventricular fibrillation. Am. J. Physiol. Heart Circ. Physiol. 293, H2702-H2709.

Houle, M. S., Altschuld, R.A., and Billman, G. E. (2001). Enhanced in vivo and in vitro responses with $\beta_{2}$-adrenergic receptor stimulation in dogs susceptible to lethal arrhythmias. J. Appl. Physiol. 91, 1627-1637.

Iellamo, F., Legramante, J. M., Massro, M., Raimondo, G., and Galante, A. (2000). Effects of a residential exercise training on baroreflex sensitivity and heart rate variability inn patients with coronary artery disease. Circulation 102, 2588-2592.

Kofuji, P., Hadley, R. W., Kieval, R. S., Lederer, W. J., and Schulze, D. H. (1992). Expression of the $\mathrm{Na}-\mathrm{Ca}$ exchanger in diverse tissues: a study using the cloned human cardiac Na-Ca exchanger. Am. J. Physiol. Cell Physiol. 263, C1241-C1249.

Kukielka, M., Seals, D. R., and Billman, G. E. (2006). Cardiac vagal modulation of heart rate during prolonged submaximal exercise in animals with healed myocardial infarctions: effects of training. Am. J. Physiol. Heart Circ. Physiol. 290, H1680-H1685.

La Rovere, M. T., Bersano, C., Gnemmi, M., Specchia, G., and Schwartz, P. J. (2002). Exercise-induced increase in baroreflex sensitivity predicts improved prognosis after myocardial infarction. Circulation 106, 945-949.

Lee, S. L., Yu, A. S. L., and Lytton, J. (1994). Tissue-specific expression of $\mathrm{Na}^{+}-\mathrm{Ca}_{2}^{+}$ exchanger isoforms. J. Biol. Chem. 269, 14849-14852.

Leitch, J. W., Newling, R. P., Basta, M., Inder, K., Dear, K., and Fletcher, P. J. (1997). Randomized trial of hospital-based exercise training after myocardial infarction: cardiac autonomic effects. J. Am. Coll. Cardiol. 29, 1263-1268.

Litwin, S. E., and Bridge, J. H. B. (1997) Enhanced $\mathrm{Na}^{+}-\mathrm{Ca}^{2+}$ exchange in the heart. Implications for excitationcontraction coupling. Circ. Res. 81, 1083-1093.

Lu, L., Mei, D. F., Gu, A. G., Wang, S., Lentzer, B., Gutstein, D. E., Zwas, D., Homma, S., Yi, G. H., and Wang, J. (2002). Exercise training normalizes altered calcium-handling proteins during development of heart failure. J. Appl. Physiol. 92, 1524-1530.

Mace, L. C., Palmer, B. M., Brown, D. A., Jew, K. N., Lynch, J. M., Glunt, J. M., Parsons, T. A., Cheung, J. Y., and Moore, R. L. (2003). Influence of age and run training on cardiac $\mathrm{Na}^{+}$/ $\mathrm{Ca}^{2+}$ exchange. J. Appl. Physiol. 95, 1994-2003.

Min, J.-Y., Sullivan, M. F., Yon, X., Feng, X., Chu, V., Wang, J.-F., Amende, I., Morgan, J. P., Philipson, K. D., and Hampton, T.G. (2002). Overexpression of $\mathrm{Na}^{+} / \mathrm{Ca}^{2+}$ exchanger gene attenuates postinfarction myocardial dysfunction. Am. J. Physiol. Heart Circ. Physiol. 283, H2466-H2471.

Nicoll, D. A., Longoni, S., and Philipson, K. D. (1990). Molecular cloning and functional expression of the cardiac sarcolemmal Na-Ca exchanger. Science 250, 562-565.

O'Connor, G. T., Buring, J. E., Yusuf, S., Goldhaber, S. Z., Olmstead, E. M., Paffenbarger, R. S. Jr., and Hennekens, C. H. (1989). An overview of randomized trials of rehabilitation with exercise after myocardial infarction. Circulation 80, 234-244.

O’Rourke, B., Kass, D. A., Tomaselli, G. F., Kääb, S., Tunin, R., and Marbán, E. (1999). Mechanisms of altered excitation-contraction coupling in canine tachycardia-induced heart failure. Circ. Res. 84, 562-570.

Ozdemir, S., Bito, V., Holemans, P., Venet, L., Mercadier, J.-J., Varro, A., and Sipido, K. R. (2008). Pharmacological inhibition of $\mathrm{Na} / \mathrm{Ca}$ exchange results in increased cellular $\mathrm{Ca}^{2+}$ load attributable to the predominance of forward mode block. Circ. Res. 102, 1398-1405.

Palmer, B. M., Lynch, J. M., Synder, S. M., and Moore, R. L. (1999). Effects of chronic run training on $\mathrm{Na}^{+}$ dependent $\mathrm{Ca}^{2+}$ efflux from rat left ventricular myocytes. J. Appl. Physiol. 86, 584-591.

Philipson, K. D., and Nicoll, D. A. (2000). Sodium-calcium exchange: a molecular prospective. Annu. Rev. Physiol.62, 111-133.

Piper, C., Bilger, J., Henrichs, E.-M., Schultheiss, H.-P., Horstkotte, D., and Doerner, A. (2000). Is myocardial $\mathrm{Na}^{+}$$\mathrm{Ca}^{2+}$ exchanger transcription a marker for different stages of myocardial dysfunction? Quantitative polymerase chain reaction of the messenger RNA in endomyocardial biopsies of patients with heart failure. J. Am. Coll. Cardiol. 36, 233-241.

Pogwizd, S. M. (2000). Increased $\mathrm{Na}^{+}-\mathrm{Ca}^{2+}$ exchanger in the failing heart. Circ. Res. 87, 641-643.

Pogwizd, S. M., Qi, M., Yuan, W., Samarel, A. M., and Bers, D. M. (1999). 
Upregulation of $\mathrm{Na}^{+}-\mathrm{Ca}^{2+}$ exchanger expression and function in an arrhthmogenic rabbit model of heart failure. Circ. Res. 85, 1009-1019.

Pogwizd, S. M., Schlotthauer, K., Li, L., Yuan, W., and Bers, D. M. (2001). Arrhythmogenesis and contractile dysfunction in heart failure: roles of sodium-calcium exchange, inward rectifier potassium current, and residual $\beta$-adrenergic responsiveness. Circ. Res. 88, 1159-1167.

Quinn, F. R., Currie, S., Duncan, A. M., Miller, S., Sayeed, R., Cobbe, S. M., and Smith, G. L. (2003). Myocardial infarction causes increased expression but decreased activity of the myocardial $\mathrm{Na}^{+}-\mathrm{Ca}^{2+}$ exchanger in the rabbit. $J$. Physiol. 553, 229-242.

Reuter, H., Pott, C., Goldhaber, J. I., Henderson, S. A., Philipson, K. D., and Schwinger, H. G. R. (2005). $\mathrm{Na}^{+}-\mathrm{Ca}^{2+}$ in the regulation of cardiac excitationcontraction coupling. Cardiovasc. Res. 67, 198-207.

Rubart, M., and Zipes, D. P. (2005). Mechanisms of sudden cardiac death. J. Clin. Invest. 115, 2305-2315.

Santacruz-Toloza, L., Ottolia, M., Nicoll, D. A., and, Philipson, K. D. (2000). Functional analysis of a disulfide bond in the cardiac $\mathrm{Na}^{+}-\mathrm{Ca}^{2+}$ exchanger. $J$. Biol. Chem. 275, 182-188.

Satoh, H., Ginsburg, K. S., Qing, K., Terada, H., Hayashi, H., and Bers, D. M. (2000). KB-R7943 block of $\mathrm{Ca}^{2+}$ influx $\mathrm{Na}^{+} / \mathrm{Ca}^{2+}$ exchange does not alter twitches or glycoside inotrophy but prevents $\mathrm{Ca}^{2+}$ overload in rat ventricular myocytes. Circulation 101, 1441-1446.

Schillinger, W., Schneider, H., Minami, K., Ferrari, R., and Hasenfuss, G. (2002). Importance of sympathetic activation for the expression of $\mathrm{Na}^{+}-$ $\mathrm{Ca}^{2+}$ exchanger in end-stage failing human myocardium. Eur. Heart J. 23, 1118-1124.

Schwartz, P. J., Billman, G. E., and Stone, H. L. (1984). Autonomic mechanisms in ventricular fibrillation induced by myocardial ischemia during exercise in dogs with healed myocardial infarctions: an experimental preparation for sudden cardiac death. Circulation 69, 790-800.

Shigekawa, M., and Iwamoto, T. (2001). Cardiac $\mathrm{Na}^{+}-\mathrm{Ca}^{2+}$ exchange: molecular and pharmacological aspects. Circ. Res. 88, 864-876.

Sipido, K. R., Volders, P. G. A., Marieka de Groot, S. H., Verdonck, F., Van de Werf, F., Wellens, H. J. J., and Vos, M. A. (2000). Enhanced $\mathrm{Ca}^{2+}$ release and $\mathrm{Na}^{+}-\mathrm{Ca}^{2+}$ exchange activity in hypertrophied canine ventricular myocytes. Potential link between contractile adaption and arrhythmogenesis. Circulation 102, 2137-2144.

Song, J., Zhang, X.-Q., Wang, J., Carl, L. L., Ahlers, B. A., Rothblum, L. I., and Cheung, J. Y. (2004). Sprint training improves contrqactility in postinfarction rat myocytes: role of $\mathrm{Na}^{+} /$ $\mathrm{Ca}^{2+}$ exchange. J. Appl. Physiol. 97, 484-490.

Steffen-Batey, L., Nichman, M. Z., Goff, D. C., Frankowski, R. F., Hanis, C. L., Ramsey, D. J., and Labarthe, D. R. (2000). Change in level of physical activity and risk of all-cause mortality or reinfarction: the Corpus Christi heart project. Circulation 102, 2204-2209.

Tibbits, G. F., Kashihara, H., and O'Reilly, K. (1989). $\mathrm{Na}^{+}-\mathrm{Ca}^{2+}$ exchange in cardiac sarcolemma: modulation of $\mathrm{Ca}^{2+}$ affinity by exercise. Am. J. Physiol. Heart Circ. Physiol. 262, C638-C643.

Wakimoto, K., Kobayashi, K., Kuro-o, M., Yao, A., Iwamoto, T., Yanaka, N., Kita, S., Nishida, A., Azuma, S., Toyoda,
Y., Omori, K., Imahie, H., Oka, T., Kudoh, S., Kohmoto, O., Yazaki, Y., Shigekawa, M., Imai, Y., Nabeshima, Y., and Komuro, I. (2000). Targeted disruption of $\mathrm{Na}^{+}-\mathrm{Ca}^{2+}$ exchanger gene leads to cardiomyocyte apoptosis and defects in heartbeat. J. Biol. Chem.275, 36991-36998.

Waldo, A. L., Camm, A. J., deRuyter, H., Friedman, P. L., MacNeil, D. J., Pauls, J. F., Pitt, B., Pratt, C. M., Schwartz, P. J., and Veltri, E. P. for SWORD Investigators (1996). Effect of d-sotalol on mortality in patients with left ventricular dysfunction after recent and remote myocardial infarction. Lancet 348, 7-12.

Wang, J., Gao, E., Song, J., Zhang, X. Q., Li, J., Koch, W. J., Tucker, A. L., Phiilipson, K. D., Chan, T.O., Feldman, A. M., and Cheung,J.Y. (2010). Phospholemman and $\beta$-adrenergic stimulation in the heart. Am. J. Physiol. Heart Circ. Physiol. 298, H807-H815.

Wei, S. K., Ruknudin, A., Hanlon, S. U., McCurley, J. M., Schulze, D. H., and Haigney, M. C. (2003). Protein kinase A hyperphosphorylation increases basal current but decreases betaadrenergic responsiveness of the sarcolemmal $\mathrm{Na}+-\mathrm{Ca} 2+$ exchanger in failing pig myocytes. Circ. Res. 92, 897-903.

Wisløff, U., Loennechen, J. P., Currie, S., Smith, G. L., and Ellingsen, Ø. (2000). Aerobic exercise reduces cardiomyocyte hypertrophy and increases contractility, $\mathrm{Ca}^{2+}$ sensitivity and SERCA-2 in rat after myocardial infarction. Cardiovasc. Res. 54, 162-174.

Xiong, W., Tian, Y., DiSilvestre, D., and Tomaselli, G. F. (2005). Transmural heterogeneity of the $\mathrm{Na}^{+}-\mathrm{Ca}^{2+}$ exchange: evidence for differential expression in normal and failing hearts. Circ. Res. 97, 207-209.
Zhang, X.-Q., Ng, Y.-C., Musch, T. I., Moore, R. L., Zelis, R., and Cheung, J.Y. (1998). Sprint training attenuates myocyte hypertrophy and improves $\mathrm{Ca} 2+$ homeostasis in postinfarction myocytes. J. Appl. Physiol. 84, 544-552.

Zhang, X.-Q., Ng, Y.-C., Musch, T. I., Zelis, R., and Cheung, J. Y. (1999). Effects of impaired $\mathrm{Ca}^{2+}$ homeostasis on contraction in postinfarction myocytes. $J$. Appl. Physiol. 86, 943-950.

Zhang, Y. H., and Hancox, J. C. (2009). Regulation of cardiac $\mathrm{Na}^{+}-\mathrm{Ca}^{2+}$ exchanger activity by protein kinase phosporylation - still a paradox? Cell Calcium 45, 1-10.

Conflict of Interest Statement: The authors declare that the research was conducted in the absence of any commercial or financial relationships that could be construed as a potential conflict of interest.

Received: 04 November 2010; paper pending published: 21 December 2010; accepted: 04 February 2011; published online: 14 February 2011.

Citation: Kukielka M, Holycross BJ and Billman GE (2011) Endurance exercise training reduces cardiac sodium/calcium exchanger expression in animals susceptible to ventricular fibrillation. Front. Physio. 2:3. doi: 10.3389/fphys.2011.00003

This article was submitted to Frontiers in Exercise Physiology, a specialty of Frontiers in Physiology.

Copyright (c) 2011 Kukielka, Holycross and Billman. This is an open-access article subject to an exclusive license agreement between the authors and Frontiers Media $S A$, which permits unrestricted use, distribution, and reproduction in any medium, provided the original authors and source are credited. 